\title{
ガウス曲率とシエルの座屈 V
}

曲げを伴う殼の座屈 (4), Galerkin 法の意義と変分式

正会員坪 井善 勝*

序

II 〜IV章で “曲げを伴う殸の座屈”を論じた。I章を 除き解析法として釣り合い式のみならず，適合条件式に も Galerkin 法を用いている。よって本論は Galerkin 法と変分式との関連を論じ解析手法の論拠を明らかにし たものである。

\section{§1．Galerkin 法の意義およひ変分式}

\subsection{Galerkin 法の意義}

“曲げを伴う殼の座屈”（II～IV) の解注釣り合い式だ けでなく, 適合条件式にも Galerkin 法を用いているの で, Galerkin 法のもつ意義の解明は極めて重要である。

Ritz-Galerkin 法は変分法において Euler 方程式を誘 導することなく, 変分式を直接解くいわゆる直接法に属 するものである。その変分式の物理的意義は,

(a) 釣り合い式は Elastic Potential が変位 $w の$ 変分 $\delta w$ に対してもつ停留原理,すなわち Virtual Work の原理である。そしてこの変分についての束縛条件 (Constraint Condition) は適合条件式である。この原 理は線型，非線型共成立する。(1.2)

(b) 適合条件式は Complementary Energy が応力 (応力関数 $\phi$ ) の変分 $\delta \phi$ に対してもつ停留原理すなわ ち Complementary Virtual Work の原理であって,こ の変分についての束縛条件 (Constraint Condition) は 验り合い式である。この原理は線型問題だけに成立し, 非線型問題では成立しない $(1.2)$ 。

ここに Galerkin 式に（a）のみを用いるためには，

1. 適合条件式だけは 完全解を求め, Galerkin 法は 釣り合い式だけに用いる。

2. すべてが釣り合い式である変位式に Galerkin 法 を適用する。

1, 2 が通常行われている解析法である。しかし変分法 における停留原理は，この場合釣り合い式も適合条件も すでに求まっているから，これらが変分式から Euler 方 程式として誘導される時の形は次の通りでなければなら ない。

$$
\begin{aligned}
& \iint \delta w\left[D \Delta \Delta w-a \phi,{ }_{y y}-b \phi,_{x x}+2 c \phi, x y\right. \\
& \quad-w,_{x x} \phi,,_{y y}-w,,_{y} \phi, x x \\
& \left.\quad+2 w,_{x y} \phi, x y-p\right] d x d y=0 \ldots \ldots \ldots \ldots
\end{aligned}
$$

$$
\begin{aligned}
& \iint \delta \phi\left[\frac{1}{E t} \Delta \Delta \phi+a w,_{y y}+b w,_{x x}-2 c w, x y\right. \\
& \left.\quad-w, y_{x}{ }^{2}+w,_{x x} w,_{y y}\right] d x d y=0 \cdots \cdots(1-2)^{* 1}
\end{aligned}
$$

ここに $a, b, c$ は 2 次曲面の曲率, 据率であり, $[\mathrm{J}=$ 0 はそれぞれ釣り合い式，適合条件式である。 $\iint は$ 全 面積についての積分である。

いわゆる直接法における Galerkin 式は次の通りであ る。

$w \rightarrow w+\delta w, \quad \phi \rightarrow \phi+\delta \phi$

なる $w$ の変分 $\delta w$ は $w$ の増分であるが $w に$ 無関倸 な微小量である。 $\phi$ についても同様である。今 $\phi, w を$ 次のように置く。

$$
\begin{gathered}
\phi=\sum_{r} \sum_{s} A_{r s} \phi_{r s}, w=\sum_{r} \sum_{s} B_{r s} w_{r s} \cdots \cdots \cdots \text { (a) } \\
こ こ に r=1,2, \cdots, i, \cdots, m ; s=1,2, \cdots, j, \cdots, n \text {,(本 }
\end{gathered}
$$
論では $\left.\phi_{r s}=w_{r s}\right) A_{r s}, B_{r s}$ は常数， $\phi_{r s}, w_{r s}$ はそれ ぞれ境界条件を満たす線型的独立な関数で, 座標関数 “Coordinate Function” と名づけるものである。独立変 数 $w$ の変分 $\delta w$ に対する $\Pi$ の変分 $\delta \Pi$ を求めるとき, $\delta w(x, y)$ は境界条件さえ満足すれば $w(x, y)$ に関倸 のない微小量である。よって

$$
\delta w=B^{\prime}{ }_{i j} w_{i j}
$$

と置くことができる。この $B^{\prime}{ }_{i j}$ は $m \times n$ 個の独立な微 小常数である。式 (b) によって式 (1-1) は $B^{\prime}{ }_{i j}$ が落 ちて $\left[D \Delta^{2} w \cdots\right]$ に単に Coordinate Function を乗じた 次の $m \times n$ 個の方程式となる*2。

$$
\iint w_{i j}\left[D \Delta^{2} w \cdots\right] d x d y=0
$$

同様に $\phi$ について次の $m \times n$ 個の方程式が成立する。

$$
\iint \phi_{i j}\left[\frac{1}{E t} \Delta^{2} \phi \cdots\right] d x d y=0
$$

この式 (c), (d) はいゔれも $\delta \Pi=0$ に相当する式であ る。よって

注 $*$ 東大名誉教授, 工博

*1 普通は $(1-1)+(1-2)=0$ の形で示されるが $\delta w, \delta \phi$

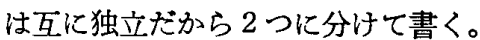

*2 $\delta \Pi$ を求める時に初めから $\delta w$ の代りに式 (b) を使って 部分積分を行って得られる式である。 


$$
\left.\begin{array}{c}
D \Delta^{2} w \cdots \cdots \equiv L_{1}(\phi, w) \\
\frac{1}{E t} \Delta^{2} \phi \cdots \cdots \equiv L_{2}(\phi, w)
\end{array}\right\}
$$

と置いたとき

$$
L_{1}(\phi, w)=0, L_{2}(\phi, w)=0
$$

は，やはり Euler 方程式である。ここで $L_{1}(\phi, w), L_{2}$ ( $\phi, w)$ に（a）を代入すれば，式 (c)，(d) は $A_{r s}, B_{r s}$ に関する $2 \times m \times n$ 個の 1 次方程式となっ $\tau, A_{r s}, B_{r s}$ が定まる。しかし式（a）で与えられる有限項の級数は 一般には Euler 方程式 (f) を満足しない。従がって式 （e）に式（a）を代入した式

$$
\left.\begin{array}{l}
L_{1} \Rightarrow L_{1}{ }^{\prime}\left(\sum_{r} \sum_{s} A_{r s} \phi_{r s}, \sum_{r} \sum_{s} B_{r s} w_{r s}\right) \\
L_{2} \Rightarrow L_{2}{ }^{\prime}\left(\sum_{r} \sum_{s} A_{r s} \phi_{r s}, \sum_{r} \sum_{s} B_{r s} w_{r s}\right)
\end{array}\right\}
$$

は "誤差関数” Error Function として扱われるもので ある(文献 5) 他)。しかし

$$
\left.\begin{array}{l}
\iint w_{i j} L_{1}^{\prime}\left(\sum_{r} \sum_{s} A_{r s} \phi_{r s}, \sum_{r} \sum_{s} B_{r s} w_{r s}\right) d x d y=0 \\
\iint \phi_{i j} L_{2}{ }^{\prime}\left(\sum_{r} \sum_{s} A_{r s} \phi_{r s}, \sum_{r} \sum_{s} B_{r s} w_{r s}\right) d x d y=0
\end{array}\right\}
$$

すなわち “直交条件の満足”によって式（h）から求ま る $A_{r s}, B_{r s}$ は $m, n \rightarrow \infty$ において式 (f) を満足する解 析解を与える。以上の解法 (直接法) が Galerkin 法で ある。

\section{2 変分式}

以下 2 種の変分式 $\left(h_{1}\right)\left(h_{2}\right)$ を論じる。

$$
\begin{aligned}
A= & \frac{E t}{2\left(1-\nu^{2}\right)}\left[\left(e_{x x}+e_{y y}\right)^{2}+2(1-\nu)\left(e_{x y}{ }^{2}-e_{x x} e_{y y}\right)\right] \\
& +\frac{D}{2}\left[\left(\kappa_{x}+\kappa_{y}\right)^{2}+2(1-\nu)\left(\kappa_{x y}{ }^{2}-\kappa_{x} \kappa_{y}\right)\right] \cdots(1-3)
\end{aligned}
$$

$A$ は Strain Energy Function,

$$
\begin{aligned}
B= & \frac{1}{2 E t}\left[\left(N_{x}+N_{y}\right)^{2}+2(1+\nu)\left(N_{x y}{ }^{2}-N_{x} N_{y}\right)\right] \\
& +\frac{1}{2\left(1-\nu^{2}\right) D}\left[\left(M_{x}+M_{y}\right)^{2}\right. \\
& \left.+2(1+\nu)\left(M_{x y}{ }^{2}-M_{x} M_{y}\right)\right] \quad \ldots \ldots \ldots \ldots \ldots(1-4)
\end{aligned}
$$

$B$ は Complementary Energy Function であり， ポテンシャルエネルギーは

$$
\iint[-p w+A] d x d y
$$

補エネルギー (Complementary Energy) は

$$
\iint B d x d y
$$

である。

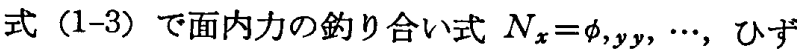
み変位式 $\kappa_{x}=w, w_{x x}, \cdots, \cdots$,

式 (1-4) で面内力の钓り合い式 $N_{x}=\phi, y y, \cdots$, モ一 メント変位式 $M_{x}=-D\left(w, w_{x x}+\nu w,{ }_{y y}\right), \cdots$

を用いた式 (1-3)，(1-4) は $A(\phi, w)=B(\phi, w)$

$$
\begin{aligned}
& =\frac{1}{2 E t}\left[(\phi, x x+\phi, y y)^{2}\right. \\
& \left.+2(1+\nu)\left(\phi, x_{x}{ }^{2}-\phi,_{x x} \phi, y y\right)\right] \\
& +\frac{D}{2}\left[\left(w, x x+w,_{y y}\right)^{2}\right. \\
& \left.+2(1-\nu)\left(w, x_{x}{ }^{2}-w,_{x x} w, y y\right)\right] \cdots
\end{aligned}
$$

である。

\section{適合条件式（線型）}

$$
f_{1}=\frac{1}{E t} \Delta^{2} \phi+a w,,_{y}+b w,_{x x}-2 c w, x y=0
$$

$z$-方向釣り合い式（線型）

$$
f_{2}=D \Delta^{2} w-p w-a \phi,,_{y}-b \phi, x x+2 c \phi, x y=0
$$

に対して, 式（d）が与えられれば

$$
\Pi=\iint\left(-p w+A-L f_{1}\right) d x d y
$$

ここに $L$ は Lagrange Factor で $\Pi$ における変数 $L$, $\phi, w$ は独立変数であり, $w$ の変分 $\delta w$ に対寸る $I I$ の 変分

$$
\delta \Pi=0
$$

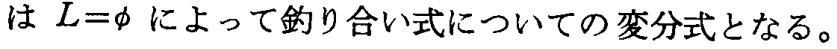

この方法を用いて $(\mathrm{d})$ に非線型適合条件式を使 5 と, 式 $\left(h_{1}\right)$ から非線型验り合い式に相当する変分式，すな わち式 (1-1) が求まる。(証明略)

一方式（e）が与えられれば

$$
\Pi=\iint\left(B-L f_{2}\right) d x d y
$$

一ここに $L$ は Lagrange Factor で $\Pi$ における変 数 $L, \phi, w$ は独立変数である一一の変分 $\delta \phi に$ 対する II の変分

$$
\delta \Pi=0
$$

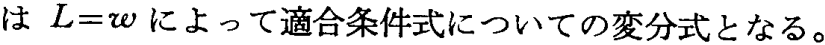
しかしこの場合に（e）に非線型釣り合い式を用いても 非線型適合条件式 (1-2) は求まらない。一非線型項 が正しく表現されないのである。(証明略) “汎関数” Functional の重要性はここにある。

\section{§2. 汎関数亡変分式}

ポテンシャルエネルギー

$$
\Pi_{0}=\iint(-p w+A) d x d y
$$

に,ひぶみ変位式に応力を Lagrange Factor とした付 帯条件 (Subsidiary Condition) を加えた式

$$
\begin{aligned}
I=\Pi_{0}+\iint[ & -\left\{e_{x x}-\left(u, x_{x}-a w+\frac{1}{2} w, x^{2}\right)\right\} N_{x} \\
& -\left\{e_{y y}-\left(v, y_{y}-b w+\frac{1}{2} w, y^{2}\right)\right\} N_{y} \\
& -\left\{2 e_{x y}-\left(u, y+v, x_{x}-2 c w\right.\right. \\
& \left.\left.+w,_{x} w, y\right)\right\} N_{x y} \\
& +\left\{\kappa_{x}-w, x x\right\} M_{x}
\end{aligned}
$$




$$
\begin{aligned}
& +\left\{\kappa_{y}-w, y_{y}\right\} M_{y} \\
& \left.+2\left\{\kappa_{x y}-w, x y\right\} M_{x y}\right] d x d y \\
& \text { 十 (境界項) }
\end{aligned}
$$

は変位 $u, v, w$ ひゔみ $e_{x x}, \cdots, \kappa_{x}, \cdots$, 応力 $N_{x}, \cdots$, $M_{x}, \cdots$, すべてが独立変数であるいわゆる汎関数 Functional であり，鷲津理論に属するものである。また Lagrange Factor が応力 $N_{x}, \cdots, M_{x}, \cdots$ であること は例えば $e_{x x}$ の変分によって応力ひらみ式

$$
N_{x}=\frac{E t}{1-\nu^{2}}\left(e_{x x}+\nu e_{y y}\right)
$$

が求まり $\kappa_{x}$ の変分によってモーメント, 曲率式 $M_{x}=$ 一D $\left(\kappa_{x}+\nu \kappa_{y}\right)$ が求まることによって証明される。

式 $(2-2)$ で

$$
\kappa_{x}=w,{ }_{x x}, \cdots
$$

を用いれば， $M_{x}, \cdots$ は消去され，面内力の釣り合い式

$$
N_{x, x_{x}}+N_{x y, y}=0, N_{y, y}+N_{x y, x}=0 \cdots \cdots(2-3)
$$
を用いて

$$
\begin{aligned}
& \iint\left(u,{ }_{x} N_{x}+v,{ }_{y} N_{y}+u,{ }_{y} N_{x y}+v,{ }_{x} N_{x y}\right) d x d y \\
& \quad=\text { (境界項) }-\iint\left[u\left(N_{x, x}+N_{x y, y}\right)\right. \\
& \left.\quad+v\left(N_{y, y}+N_{x y, x}\right)\right] d x d y=\text { (境界項) }
\end{aligned}
$$

となる。ただし本論では

$$
\begin{gathered}
\int_{0}^{a} \int_{0}^{a} u,{ }_{x} N_{x} d x d y=\int_{0}^{a}\left[u N_{x}\right]_{0}^{a} d y \\
-\int_{0}^{a} \int_{0}^{a} u N_{x, x} d x d y
\end{gathered}
$$

において $x=0, a ; N_{x}=0, \cdots$

また

$$
\begin{gathered}
\int_{0}^{a} \int_{0}^{a} u, y N_{x y} d x d y=\int_{0}^{a}\left[u N_{x y}\right]_{0}^{a} d x \\
-\int_{0}^{a} \int_{0}^{a} u N_{x y}, y d x d y
\end{gathered}
$$

において $y=0, a ; u=0, \cdots$ である。よって（境界項） $=0$ である。

一方（2-3）の代りに応力関数 $\phi$ を用いて

$$
N_{x}=\phi, y y, N_{y}=\phi, x x, N_{x y}=-\phi, x y
$$

また式（2-5）を応力ーひゔみ式

$$
e_{x x}=\frac{1}{E t}\left(N_{x}-\nu N_{y}\right), \cdots,
$$

に入れて式 (2-2) に代入すると式 (2-7) が求まる。 本式は $\phi, w$ を独立変数とした汎関数であり, 平面板に ついて求めた熟津式（文献 6)，p. 165）に曲率 $a, b, c$ の項（第 6 行）を加えた式である。

$$
\begin{aligned}
\Pi=\iint[ & -\frac{1}{2 E t}\left\{(\phi, x x+\phi, y y)^{2}\right. \\
& \left.+2(1+\nu)\left(\phi, x y^{2}-\phi, x_{x} \phi, y y\right)\right\} \\
& +\frac{D}{2}\{w, x x+w, y y)^{2}
\end{aligned}
$$

$$
\begin{aligned}
& \left.+2(1-\nu)\left(w, x y^{2}-w, x x w, y y\right)\right\} \\
& -p w \\
& -\left\{a \phi,{ }_{y y}+b \phi,{ }_{x x}-2 c \phi,{ }_{x y}\right\} w \\
& +\frac{1}{2}\left\{\phi,{ }_{y y} w, x^{2}+\phi,{ }_{x x} w^{\prime}, y^{2}\right. \\
& \left.\left.-2 \phi,{ }_{x y} w,{ }_{x} w,{ }_{y}\right\}\right] d x d y \\
& \text { 十 (境界項) }
\end{aligned}
$$

本論の境界条件では (境界項) $=0$ である。

式 $(2-7)$ の $w$ の変分 $\delta w に$ 対する $\Pi$ の変分 $\delta \Pi=0$ は式 (1-1) であり， $\phi$ の変分 $\delta \phi に$ 対する $I \Pi$ の変分 $\delta \Pi=0$ は式 $(1-2)$ である。境界項の変分は本論の境界 条件ではいゔれも 0 である。 $a, b, c$ は $z=z(x, y)$ に ついて一般に $z, x x, z, y y, z, x y$ で置き代えられ，また ひづみ変位式には Vlasov 式(Donnell 式の抎張) を用 いても Marguerre 式を用いても同じ式が求まる。

\section{遍 記}

1. 本論は parametric coefficient of Gaußian curvature $\lambda$ の項をすべての論議の中で努めて explicit に 表現することを試みた。正方形平面（一辺 $a$ ）でなく辺 長比 $\bar{\lambda}=b / a$ は $\lambda$ と共に重要である。えを入れて論じる ことは基本式, 解析法共本論に従って論じることができ る。しかし本論はスに重点を置いてえには触れなかっ た。

2. 外圧として $p=$ const. (follower force), 境界条 件として周辺単純支持を条件としたことは，前者につい ては海中構造物が念頭にあったことと，pが follower force でない外力でも flat shell ではかなりの近似度を もって一様な分布荷重（重力）を表わすからである。後 者については境界条件を満足する関数が単純であり，同 時に Galerkin 式が $i, j \rightarrow 1,3, \cdots, \infty$ において線型式で 完全解（Navier 形式）に一致するからである。また同 時に解における入の表現がつねに explicit であるため である。そして 2 重級数ではあるが Fourier 級数とし ての性格が他の境界条件におけるよりも明確であるから である。-Dilichlet の条件の満足，各項の直交性など。

3. 曲げモーメントは特定境界条件を与えない限り面 内力と共存するから，固定度の緩い flat shell の境界条 件の理想化として本境界条件を選んだ。ただし 4 点（4 隅点）の移動は 0 としてある。完全固定や 4 点もロ一 ラーであるような自由辺をもつ境界条件もまた同時に重 要であるとは考える。しかしこれらについては個々の特 定な $\lambda$ について座届問題を論じる他はなく, Fourier 形 式で処理するのは線型問題と違って却って繁雑であり， また解の収㪘性についての検討が困難になる。従がって 個々の特別な実用問題であれば差分法 (Dynamic Relaxation を含む) や，F.E.M の方がむしろ有効であると 思われる。だが本論の主旨はコンピューター計算前にお 
けるシェルの座屈挙動の解明にある。

4. 文献 13) は A.R. Robinson 教授の下での Dr. Philosophy の論文で Proc. A.S.C.E. に発表された短 論文であり，Gauß曲率の変化を考えたことでは筆者の 論文に近いものの一つである。

本論文は境界条件を $u=v=w=M_{n}$ （法線方向モ一メ ント) $=0$ としているから筆者のローラー支持に対して ピン支持を扱っている。従がって曲げ忘力の少い膜応力 からの座屈変形を取り扱かったものである。釣り合い式 をポテンシャルエネルギーの $u, v, w$ に関する変分で求 めているから, flat shell ではあるが応力関数を用いな いから面内力の釣り合い式に線型方程式を使ら必要汇な い。用いた解析法は Ritz 法であるが，完全にコンピュ 一ターに依存した計算で, 数值計算には Newton Raphson iteration 法が適用されたと記されている。また解 の収㪘誤差はコンピューター使用時間との関係で定ま る。実利的な解析で現代の流行ではあるが，Fourier 解 析との関係が不明である。

なお筆者のれについての explicit な表現は本論文に はない。

5. 第II章の 1 例の計算で $\lambda=-1$ (H.P.) に対する座 屈荷重は $P_{c r} \rightarrow \infty$ であるという解釈は必ずしも必要で はない。第III章で論じた通り上部坐屈荷重に達する前の 反曲点座屈を筆者は“擬似座屈荷重”と仮称したが，こ れはいわゆる通常の座屈現象ではなく，一種の大挩み現 象である。かつ第 III 章では $\lambda=-1$ は暁み 0 に反曲点 をもつ座屈変形曲線が生じる曲面であると論じた。従が って $\lambda=-1$ に掠いて $P_{c r}=0$ であっても, すなわち固 有值として $P_{c r}=0$ が求まっても物理的には不都合はな い筈である*3。第II章で述べた通り 1 例についての計算 結果では $\lambda \doteqdot-0.40$ で $P_{c r}-\lambda$ 曲線に明確な折れ線が現 われている。このことは $1 \geq \lambda \geq-0.40$ では座屈現象が $\lambda<-0.40$ では “擬似座屈現象” が荷重暁み曲線を支配 すると言えそうである。これらはいられれも上部座屈が生 じる前の座屈についてである。

6. 2 を変数とした座屈問題については今後の問題と して，負のガウス曲率の領域においてより明確な知見が 必要である。一方筆者および名須川良平はアクリル模 型, ロータリーポンプによる内部空気圧低減による荷重 下で，球，円筒，H.P. の座屈現象を実験的に解明する ことを心掛けた。定量的結論は発表できる段階ではない が，第 1 回実験で球 $(\lambda=1)$ では爆裂，円筒 $(\lambda=0)$ で は座屈波形が明膫に生じる座屈, H.P. $(\lambda=-1)$ では座
屈現象は観察されなかった。また第 2 回実験では球は座 屈，他は第 1 回実験と同じであった。

\section{謝 辞}

本論をまとめるに当り，当研究室の山本理恵子（式の check, コンピュータープログラム作成，演算)，中村輝 男博士（日大生産工- $\mathrm{V}$ 章 $の$ check）羽切道雄 (演算) および東北大伊藤敬一（第 I 章変位式による $P_{c r}-\lambda$ 曲 線，第 II 章の例題を別のプログラムで解く), 諸氏の労 を謝す。また管者が余り魅力を感じなかった Galerkin 法さらに変分法に興味を植えつけて下さった㠇津教授 （東大工, 航空）の御親切と, discussion, 短い時間では あるが，Pian 教授 (M.I.T.) との discussion に謝意 を表する。 I-V 章を通じて常に督促，激励の言葉を贈 られた鹫津教授には重ねて深謝する。

\section{参 考 文 献}

1) Love : Mathematical Theory of Elasticity (1944).

2) Kh.M. Mushtari \& K.Z. Galimov : Nonlinear Theory of Thin Shells (1957).

3) S. Timoshenko \& J.M. Gere : Theory of Elastic Stability (1961)

4) Y. Tsuboi \& N. Tosaka : Nonlinear Theory of Thin Shells (1970), Technology Reports of Tohoku University, 本論の文献化 W.T. Chien (1944), Th. von Ka'rma'n \& H.S. Tsien (1941), W.T. Koiter (1966) らが挙げられている。

（以トシェルの基本式に関するもの）

5) S. Sokolnikoff : Mathematical Theory of Elasticity (1956).

6) K. Washizu : Variational Method in Elasticity and Plasticity (1968).

7) A.E. Green \& J.E. Adkins : Large Elastic Deformations (1960).

8) Thin-Shell Structures, edited by Y.C. Fung \& E.E. Sechler (1974).

9) Nonlinear Elasticity, edited by R.W. Dickey (1973).

（以上变分法㧍よび基本式に関係するもの）

10) K.M. Leet : Study of Stability in the Hyperbolic palaboloid (1966), Proc. A.S.C.E. (Skewed H.P. Shell の実験)。

11) M. Sunagawa : A Note on the Stability of Shells 他 (砂川博士の一連の実験).

12) N. Yamaki : Buckling of Circular Cylindrical Shells under External Pressure, Rep. Inst. High Sp. Mech, Japan, Vol. 20 (1968/1969), No. 196 (他東北大流体研 八巻教授研究室のシエル座屈解析に関する一連の研究, および東北大工・建・内山教授研究窒の H.P. シェルに 関する一連の研究).

13) R.H. Leicester : Finite Deformations of Shallow Shells (1968), Proc. A.S.C.E., EM 6,1968 (追記で解説)

注 *8 伊藤敬一（東北大）のコンピェータープログラムでは, $\lambda=-1$ で $p_{c r}=0$ を算出している。 


\title{
S Y N O P S I S
}

U.D.C. 624.074 .4

\section{PARAMETRIC STUDY OF ELASTIC BUCKLING OF SHELLS WITH REFERENCE TO GAUSSIAN CURVATURE}

\author{
Part V : Buckling of Shells in Bending State-Galerkin's Method \\ and Variational Problems of Elastic Buckling of Shells-
}

by YOSHIKATSU TSUBOI, Member of A.I.J.

In the preceding report (Part II $\sim$ IV), the author derived the formulae for the buckling problems of flat shells in bending state, by means of Galerkin's method which was applied not only for the equilibrium equation but also for the compatibility equation.

In this report, for proving the applicability of the above method to the compatibility equation as well as to the equilibrium equation, the author dicussed the relations among the Galerkin's method, i.e. direct method of variational problems, Euler equations and also the functionals for the compatibility equation and the equilibrium equation of the flat shells. 